\title{
The Impacts of Different Government Tax Modes under EPR Regulation
}

\author{
Jie Wu \\ Department of Management Science and Engineering, East China University of Science and Technology, \\ Shanghai 200237, China; \\ josie.wj@foxmail.com
}

Keywords: Extended Producer Responsibility (EPR), Tax Modes, Stackelberg Game Model

\begin{abstract}
In this paper, we investigate a system where the policymaker acts as the leader and the manufacturer and recycler act as followers. The policymaker collects tax from manufacturer and fully subsidize the recycler. Considering extended producer responsibility (EPR) regulation and using Stackelberg game model, we discuss the impacts of these three tax modes on environment and economy, accordingly to give some suggestions to policymaker.
\end{abstract}

\section{Introduction}

Rapid economic growth and the rapid development of urbanization have caused significant environmental problems, such as energy / resource depletion, air / water pollution and climate change. China has introduced relevant policies to the reinforce extended producer responsibility (EPR) regulation (Esenduran et al., 2012) and promote recycling efficiency. However, on the 2017 International Conference on Electrical and Electronic Product Recycling Technology and Producer Responsibility Extension System, we heard some different voice about the status of EPR in China. The largest question is that the subsidy is far from enough, which is probably because the tax collected from manufacturer is not be fully used to subsidize recycler and accordingly the recycling work cannot be promoted greatly.

Many researchers have investigated about the impacts of types of subsidies on the environment and economy and often take the view of optimal social welfare, which cannot solve the problem of maximizing use of tax. What's more, many researchers don't consider about the importance role of extended producer responsibility. Therefore, considering EPR mechanism, this paper designs a system of three tax modes collected from manufacturer to fully subsidize recycler, using Stackelberg game model. We discuss the impacts of these three modes on environment and economy, accordingly to give some suggestions to policymaker.

\section{Model setup}

We consider a system of a policymaker, a manufacturer and a recycler, where the policymaker acts as a leader, and the manufacturer and the recycler act as followers. To solve the problem that tax is much less than subsidy, the policymaker collects tax $t$ from the manufacturer, and which is all used to subsidize the recycler to achieve the goal of improving recovery and reducing environmental pollution. That is to say, the tax $t$ is equal to the subsidy $s$ in our assumption. Accordingly, the manufacturer has to afford the tax besides the production cost $C_{m}$, and the inverse demand function is given by $p=1-Q$, where $Q$ is the manufacturer's production quantity. Then with the incentive of subsidy, the recycler collects and recycles the used products, but recycling and processing capacity is limited, that is to say, the recycling rate is $r$. Therefore, some products have not been recycled, denoted by $(1-r) Q$, which will produce environmental pollution. We assume environmental 
pollution of each of the non-recycled products is $\lambda$. In addition, the difficulties of recycling are the cost of recycling, $C_{r}$, and the cost of recycling network construction $I$. We refer to Savaskan et al. (2004) research on the recycling of waste household appliances and set $I=b r^{2}$, where $b$ is the difficulty factor for recycling. In this paper, we use the funds balance model to solve the biggest problem of WEEE recycling in China, tax is far from enough for subsidy. That is to say, we assume the tax $t$ is equal to subsidy $s$ in this paper. Therefore, to discuss the impacts of tax policy under EPR restriction, we have the profit function for manufacturer:

$$
\Pi_{m}(Q)=\left(p-C_{m}\right) Q-t=\left(1-Q-C_{m}\right) Q-t
$$

And accordingly, the profit function for recycler is:

$$
\Pi_{c}(r)=\left(s-C_{r}\right) r Q-I=\left(s-C_{r}\right) r Q-b r^{2}
$$

Referring to Atasu (2009) research, we assume that the environment impact is:

$$
\Pi_{E}(\lambda)=\lambda(1-r) Q
$$

\section{Optimal Decisions}

This paper discusses the impacts of three tax modes on economic profits of manufacturer and recycler and on environmental pollution reduction.

\subsection{Optimal decisions in the case of fixed tax}

In the case of fixed tax, i.e $t_{1}=T$, which is dependent of any parameter, the profit of manufacturer is:

$$
\Pi_{m}^{(1)}(Q)=\left(p-C_{m}\right) Q-T=\left(1-Q-C_{m}\right) Q-T
$$

And the function of recycler's profit is:

$$
\Pi_{c}(r)=\left(s-C_{r}\right) r Q-I=\left(s-C_{r}\right) r Q-b r^{2}
$$

Since under this system designed by policymaker, tax collected from manufacturer is all used to subsidize recycler, i.e. $T=s$, so we have the optimal decisions of manufacturer and recycler are:

$$
\begin{aligned}
Q^{(1)} & =\frac{1-C_{m}-T}{2} \\
r^{(1)} & =\frac{\left(1-C_{m}-T\right)\left(\sqrt{C_{r}^{2}+32 b T /\left(1-C_{m}-T\right)^{2}}-C_{r}\right)}{8 b}
\end{aligned}
$$

Accordingly, the equilibrium profits of manufacturer and recycler and the environmental impact in the case of fixed tax are:

$$
\begin{aligned}
& \Pi_{m}^{(1)}(Q)=\frac{\left(1-C_{m}\right)^{2}-T^{2}}{4}-T \\
& \Pi_{c}^{(1)}(r)=\frac{\left(s-C_{r}\right)^{2}\left(1-C_{m}-T\right)^{2}}{16 b}=\frac{\left(1-C_{m}-T\right)^{2}}{64 b}\left(\sqrt{C_{r}^{2}+32 b T /\left(1-C_{m}-T\right)^{2}}-C_{r}\right)^{2} \\
& \prod_{E}^{(1)}=\lambda(1-r) Q=\frac{8 b-\left(1-C_{m}-T\right)\left(\sqrt{C_{r}^{2}+32 b T /\left(1-C_{m}-T\right)^{2}}-C_{r}\right)}{16 b}\left(1-C_{m}-T\right) \lambda
\end{aligned}
$$

\subsection{Optimal decisions in the case of variable tax correlated with manufacturer's profit}

In the case of variable tax correlated with manufacturer' profit, i.e. $t_{2}=\Pi_{m} \cdot \alpha$, where $\alpha$ denotes the portion of manufacturer's profit used to take environmental responsibility, so the profit of manufacturer is:

$$
\Pi_{m}^{(2)}(Q)=\left(p-C_{m}\right) Q-t_{2}=\left(p-C_{m}\right) Q-\left(p-C_{m}\right) Q \cdot \alpha=\left(1-Q-C_{m}\right) Q(1-\alpha)
$$

The function of recycler' profit and the policy of tax fully used for subsidy are both the same to scenario 4.1, so we have the optimal decisions of manufacturer and recycler are:

$$
\begin{aligned}
& Q^{(2)}=\frac{1-C_{m}}{2} \\
& r^{(2)}=\frac{\left(s-C_{r}\right)\left(1-C_{m}\right)}{4 b}=\frac{\left(\sqrt{C_{r}^{2}+8 b \alpha}-C_{r}\right)\left(1-C_{m}\right)}{8 b}
\end{aligned}
$$


Accordingly, the equilibrium profits of manufacturer and recycler and the environmental impact in the case of variable tax correlated with manufacturer profit are:

$$
\begin{aligned}
& \Pi_{m}^{(2)}(Q)=\frac{\left(1-C_{m}\right)^{2}(1-\alpha)}{4} \\
& \Pi_{c}^{(2)}(r)=\frac{\left(s-C_{r}\right)^{2}\left(1-C_{m}\right)^{2}}{16 b}=\frac{\left(\sqrt{C_{r}^{2}+8 b \alpha}-C_{r}\right)^{2}\left(1-C_{m}\right)^{2}}{64 b} \\
& \prod_{E}^{(2)}(\lambda)=\lambda(1-r) Q=\frac{8 b-\left(1-C_{m}\right)\left(\sqrt{C_{r}^{2}+8 b \alpha}-C_{r}\right)}{16 b}\left(1-C_{m}\right) \lambda
\end{aligned}
$$

\subsection{Optimal decisions in the case of variable tax correlated with manufacturer's production quantity}

In the case of variable tax correlated with manufacturer's production quantity, i.e. ${ }^{t}=\beta Q$, where $\beta$ denotes the tax payed by manufacturer per product, so the profit of manufacturer is:

$\Pi_{m}^{(3)}(Q)=\left(p-C_{m}\right) Q-t_{3}=\left(1-Q-C_{m}-\beta\right) Q$

The function of recycler' profit and the policy of tax fully used for subsidy are both the same to scenario 4.1, so we have the optimal decisions of manufacturer and recycler are:

$$
\begin{aligned}
Q^{(3)} & =\frac{1-C_{m}-\beta}{2} \\
r^{(3)} & =\frac{\left(s-C_{r}\right)\left(1-C_{m}-\beta\right)}{4 b}=\frac{\left(\sqrt{C_{r}^{2}+16 b \beta /\left(1-C_{m}-\beta\right)}-C_{r}\right)\left(1-C_{m}-\beta\right)}{8 b}
\end{aligned}
$$

Accordingly, the equilibrium profits of manufacturer and recycler and the environmental impact in the case of variable tax correlated with manufacturer profit are:

$$
\begin{aligned}
& \Pi_{m}^{(3)}(Q)=\frac{\left(1-C_{m}-\beta\right)^{2}}{4} \\
& \prod_{c}^{(3)}(r)=\frac{\left(s-C_{r}\right)^{2}\left(1-C_{m}-\beta\right)^{2}}{16 b}=\frac{\left(\sqrt{C_{r}^{2}+16 b \beta /\left(1-C_{m}-\beta\right)}-C_{r}\right)^{2}\left(1-C_{m}-\beta\right)^{2}}{64 b} \\
& \prod_{E}^{(3)}(\lambda)=\lambda(1-r) Q=\frac{8 b-\left(1-C_{m}-\beta\right)\left(\sqrt{C_{r}^{2}+16 b \beta /\left(1-C_{m}-\beta\right)}-C_{r}\right)}{16 b}\left(1-C_{m}-\beta\right) \lambda
\end{aligned}
$$

\section{Policy simulations}

In this section, we compare the impacts of three tax modes on economic profits of manufacturer and recycler and on environmental pollution reduction through numerical examples. This paper refers to the numerical example of TCL Corporation in Zhou (2017), where $C_{m}=0.7897, C_{r}=0.235, b=0.022, \lambda=1$, since TCL Corporation is one of largest electronics enterprises.

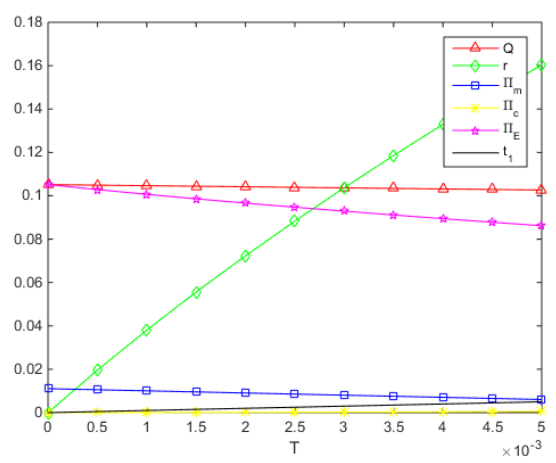

Fig.1 Optimal decisions in the case of fixed tax 


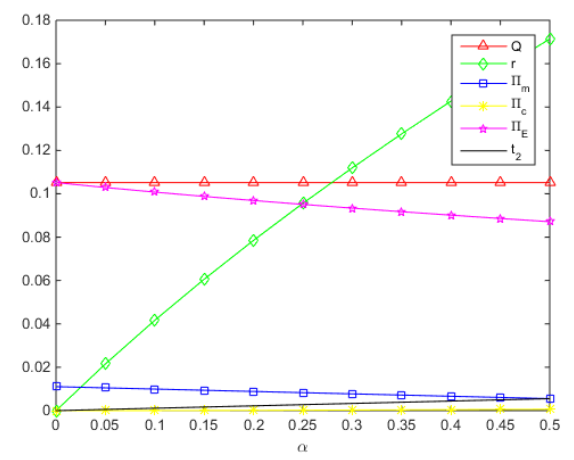

Fig.2 Optimal decisions in the case of variable tax correlated with manufacturer's profit

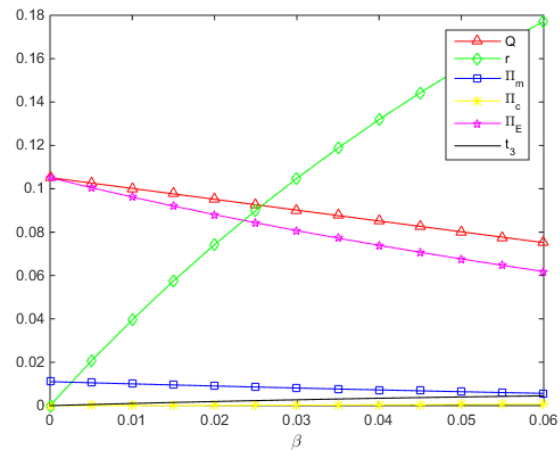

Fig.3 Optimal decisions in the case of variable tax correlated with manufacturer's production quantity

From Figs. 1-3, we can see directly that these three tax modes can promote the recycling rate and reduce environment impact greatly, which indicates that the three tax modes under this system all can have positive effects on improving recycling and reducing environmental pollution.

Comparing Figs. 1-3, variable tax correlated with manufacturer's production quantity has the most impact on environmental impact and production quantity, since the change of three tax modes' curves are similar. This is because the third tax mode positively correlated with production quantity, which results in greater decrease in the quantity with the increase in quantity-correlated tax than with other two tax modes. In addition, we can see from environment impact function that the quantity is one of two main factors causing environment impact.

These three figs also indicate that three tax modes reduce the manufacturer's profit and make recycler obtain not much profit, though. This is because the policymaker pursues for the reduction of environment pollution at the cost of economy loss.

\section{Conclusions}

Former researchers have made great effort to motivate recycling work and reduce environment pollution. This paper designs the EPR system, which can promote recycling rate and reduce environment impact, though may restrain manufacturer's and recycler's economy a little. To conclude, we suggest that the policymaker can choose the first two tax modes, fixed tax and variable tax correlated with manufacturer's profit, when the environment pollution is not too serious. This is because the first two tax modes can reduce environment impact but not do great harm to economy development. However, if the environment pollution is serious at now, we suggest the policymaker to choose the variable tax correlated with manufacturer's production quantity, which can play an important role in reducing environment impact at the cost of restraining economic development.

\section{References}

[1] Atalay A, Van W L N, Miklos S. Efficient Take - Back Legislation[J]. Production \& Operations 
Management, 2010, 18(3):243-258.

[2] Savaskan, Canan R, Bhattacharya, et al. Closed-Loop Supply Chain Models with Product Remanufacturing[J]. Management Science, 2004, 50(2):239-252.

[3] Esenduran G, Kemahlioğlu-Ziya E, Swaminathan JM. Product take-back legislation and its impact on recycling and remanufacturing industries. Springer 2012.

[4] Zhou W, Zheng Y, Huang W. Competitive advantage of qualified WEEE recyclers through EPR legislation[J]. European Journal of Operational Research, 2016, 257(2):641-655. 